\title{
Experimental and theoretical investigation of the complexation of methacrylic acid and diisopropyl urea
}

DOI:

10.1016/j.saa.2016.07.005

\section{Document Version}

Accepted author manuscript

Link to publication record in Manchester Research Explorer

\section{Citation for published version (APA):}

Pogány, P., Razali, M., \& Szekely, G. (2017). Experimental and theoretical investigation of the complexation of methacrylic acid and diisopropyl urea. Spectrochimica Acta - Part A: Molecular and Biomolecular Spectroscopy, 170, 69-76. https://doi.org/10.1016/j.saa.2016.07.005

\section{Published in:}

Spectrochimica Acta - Part A: Molecular and Biomolecular Spectroscopy

\section{Citing this paper}

Please note that where the full-text provided on Manchester Research Explorer is the Author Accepted Manuscript or Proof version this may differ from the final Published version. If citing, it is advised that you check and use the publisher's definitive version.

\section{General rights}

Copyright and moral rights for the publications made accessible in the Research Explorer are retained by the authors and/or other copyright owners and it is a condition of accessing publications that users recognise and abide by the legal requirements associated with these rights.

\section{Takedown policy}

If you believe that this document breaches copyright please refer to the University of Manchester's Takedown Procedures [http://man.ac.uk/04Y6Bo] or contact uml.scholarlycommunications@manchester.ac.uk providing relevant details, so we can investigate your claim.

\section{OPEN ACCESS}




\title{
Experimental and theoretical investigation of the complexation of methacrylic acid and diisopropyl urea
}

\author{
Peter Pogány ${ }^{1,2}$, Mayamin Razali ${ }^{3}$, Gyorgy Szekely ${ }^{3, *}$
}

1, Department of Inorganic and Analytical Chemistry, Budapest University of Technology and Economics, Szent Géllert tér 4, Budapest 1111, Hungary

2, Spectroscopic Research, Gedeon Richter Plc., Gyömröi út 19-21., Budapest 1103, Hungary

3, School of Chemical Engineering \& Analytical Science, The University of Manchester, The Mill, Sackville street, Manchester M13 9PL, United Kingdom

* Corresponding author: gyorgy.szekely@ manchester.ac.uk, +44(0)161306 4366

Keywords: NMR titration, DFT, host-guest chemistry, molecular recognition, binding characterisation

Graphical Abstract:

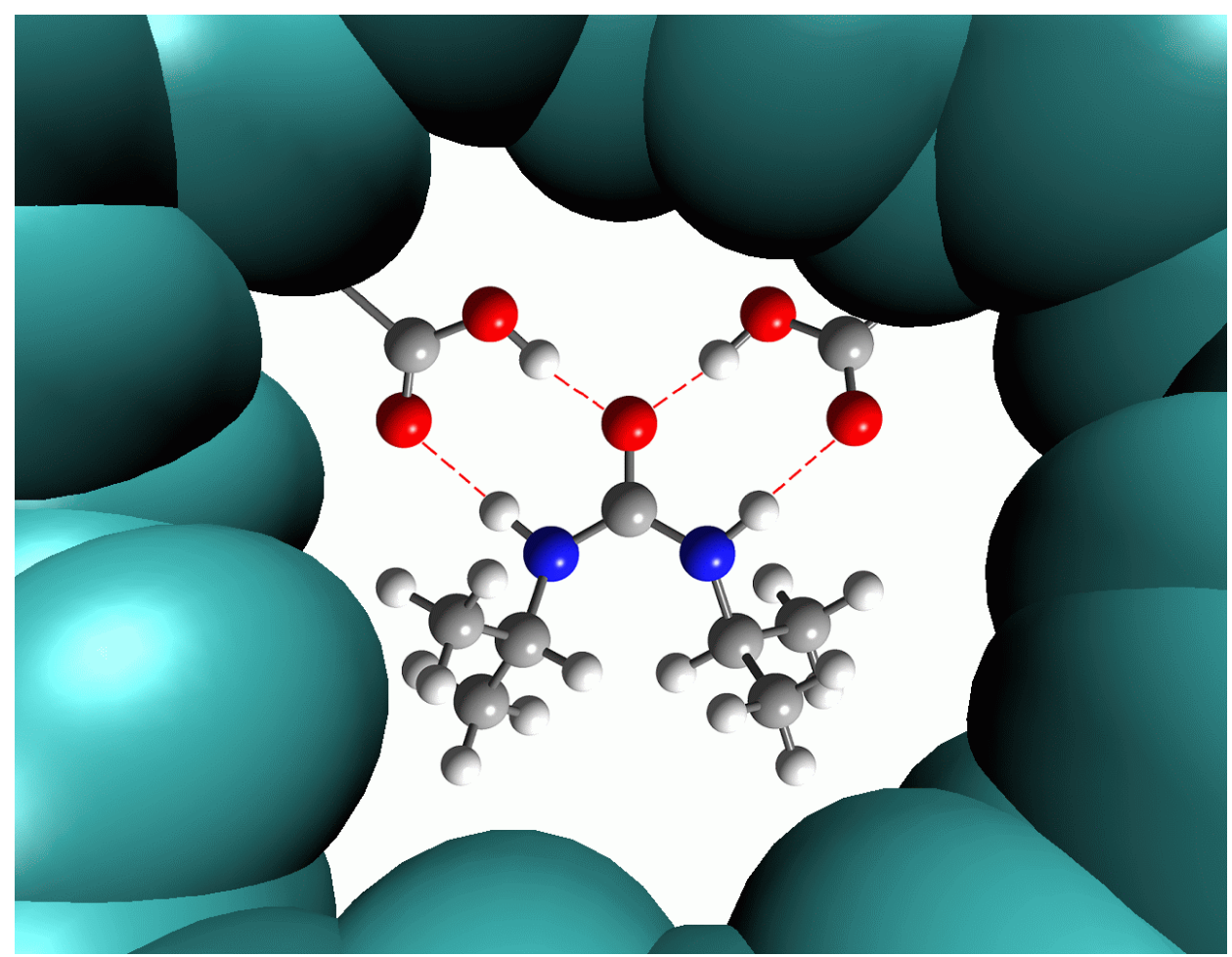




\begin{abstract}
The present paper explores the complexation ability of methacrylic acid which is one of the most abundant functional monomer for the preparation of molecularly imprinted polymers. Host-guest interactions and the mechanism of complex formation between methacrylic acid and potentially genotoxic 1,3diisopropylurea were investigated in the pre-polymerization solution featuring both experimental (NMR, IR) and in silico density functional theory (DFT) tools. The continuous variation method revealed the presence of higher-order complexes and the appearance of self-association which were both taken into account during the determination of the association constants. The quantum chemical calculations - performed at B3LYP 6$311++\mathrm{G}(\mathrm{d}, \mathrm{p})$ level with basis set superposition error (BSSE) corrections - are in agreement with the experimental observations, reaffirming the association constants and justifying the validity of computational investigation of such systems. Furthermore, natural bond orbital analysis was carried out to appraise the binding properties of the complexes.
\end{abstract}

\title{
1. Introduction
}

Molecular imprinting is a versatile technique for the preparation of intelligent materials exhibiting selective molecular recognition towards a template. ${ }^{1}$ The self-assembly of the template molecule and the functional monomer in the pre-polymerisation solution yields selective binding cavities with complementary functionalities and topographies to the template. Imprinting is usually based on reversible non-covalent interactions, and one of the most common functional monomers is methacrylic acid. ${ }^{2,3,4,5}$ This article deals with the pre-polymerisation complex of methacrylic acid (MAAH) and potentially genotoxic 1,3diisopropylurea (IPU) template which were previously used for molecular imprinting as functional monomer and template, respectively (Figure 1$)^{6}{ }^{6}$ In order to better understand the complexation mechanism, multiple methods were applied to investigate the system (NMR, IR and DFT).
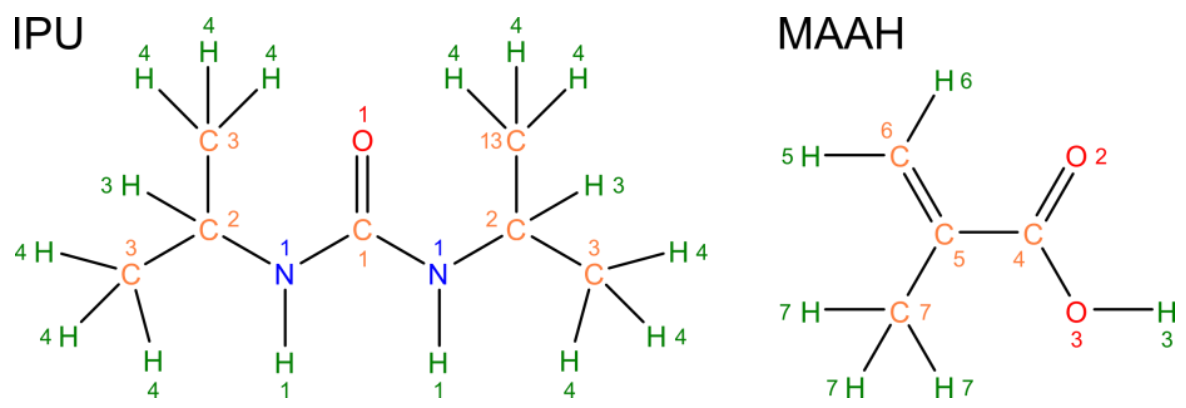

Figure 1. Structure and atom numbering of IPU template (guest), MAAH functional monomer (host).

NMR titration, a relatively common method in host-guest chemistry, was used to determine binding constants where host and guest are mixed in different ratios and the NMR spectrum of the mixture is measured. NMR titration is often used to understand complexation phenomena in macrocycle chemistry ${ }^{7,8,9}$, molecular imprinting ${ }^{10,11}$ and receptors ${ }^{12,13}$. Due to fast-exchange correlation the NMR signals of the complexes and the initial compounds do not appear separately but as their average. Both 1:1 and 1:2 
complexes and self-association of the initial compounds were considered. Although the application of IR in the investigation of binding properties of weak complexes is limited, it can provide information about the vibrations at the binding site, thus giving additional proof for complexation.

In recent years parallel to the experimental methods, the interactions between the template and the functional monomer or the polymer were explored by various in silico methods. ${ }^{14,15,16,17,18,19}$ In the earlier studies the statistical and the molecular mechanics/classical molecular dynamics studies are predominant and quantum chemical methods have only been applied in recent years due to rapid development in computational power. Most of the computational studies in the imprinting literature focus on rapid functional monomer screening. In this method semiempirical or simple Hartree-Fock techniques are employed in order to choose the most stable complexes, which are recalculated with density functional theory (DFT) methods. The ab-initio and DFT methods, which are applied in present article, are suitable for modelling the chemical interactions between the monomers and templates, describing their binding properties and the stability of the investigated complexes. The exact determination of equilibrium constants in condensed phases is, however, presently beyond the limit of these methods.

\section{Experimental}

\subsection{Materials}

1,3-diisopropylurea (IPU) was kindly provided by Hovione FarmaCiencia SA (Portugal). The chemicals were of reagent grade or higher and used as received from Sigma-Aldrich. Anhydrous solvents were stored over molecular sieves.

\subsection{Analytical methods}

\subsubsection{NMR and IR methods}

The ${ }^{1} \mathrm{H}$ NMR spectra were recorded at $25^{\circ} \mathrm{C}$ within a deviation of $0.2{ }^{\circ} \mathrm{C}$. Chemical shifts $(\delta)$ are reported in ppm, with respect to the solvent peak of deuterated chloroform being $7.26 \mathrm{ppm}^{20}$. The following abbreviations are used in the discussion: $\mathrm{s}=$ singlet, $\mathrm{d}=$ doublet, $\mathrm{t}=$ triplet, $\mathrm{q}=$ quadruplet, $\mathrm{m}=$ multiplet, $\mathrm{bs}$ $=$ broad singlet. The solvent was kept under molecular sieves and handled under inert atmosphere in order to avoid contamination of the system with water which disrupts the intramolecular hydrogen bonds. For the self-association NMR experiments $1 \mathrm{mM}, 2.5 \mathrm{mM}, 5 \mathrm{mM}, 7.5 \mathrm{mM}, 10 \mathrm{mM}, 20 \mathrm{mM}, 30 \mathrm{mM}, 40 \mathrm{mM}$ IPU working solutions were prepared in $\mathrm{CDCl}_{3}$. Additionally, Continuous Variation Method (CVM) was also performed for obtaining the stoichiometry of the complex. During the CVM, the host/guest molar ratio was varied between 0 and 1 while their total concentration was kept constant at $20 \mathrm{mM}$. In CVM the host was MAAH. Furthermore, two sets of NMR titrations were carried out where IPU was titrated with MAAH: T1 (5 mM IPU) and T2 (10 mM IPU). In order to study the effect of concentration, T1 was performed from 0-2 equivalents of MAAH with respect to $5 \mathrm{mM}$ IPU, while T2 was performed from 0-5 equivalents of MAAH with respect to $10 \mathrm{mM}$ IPU. The solutions were agitated to dissolve the IPU and homogenise the solution and 
were always freshly prepared just prior to analysis. The room temperature Fourier transform infrared (FTIR) spectra of MAAH and IPU compounds and corresponding $20 \mathrm{mM}$ IPU:MAAH (1:1) complexes were measured in DCM, in the 4000-400 $\mathrm{cm}^{-1}$ region at a resolution of $4 \mathrm{~cm}^{-1}$.

\subsection{Quantum chemical methods}

Quantum chemical computations were carried out using Gaussian 03 suite of programs ${ }^{21}$, using the Becke3-Lee-Yang-Parr exchange-correlation functional ${ }^{22,23}$ in conjunction with 6-311++G(d,p) basis set. The B3LYP functional is a general functional was chosen to be accurate with more calculated properties and this functional was used in most of the previous DFT studies ${ }^{24,25}$. Diffuse functions in the basis set (denoted with ++ ) were chosen to obtain better results for the hydrogen-bonded systems ${ }^{26,27}$. The minimum character of the stationary points obtained by geometry optimizations was checked by vibrational frequency calculations. The solvent effects were considered implicitly by the polarizable continuum model (PCM) ${ }^{28,29,30}$. The solvation energies could be calculated only on the optimised geometries of the isolated structures, since the starting unequilibrated structures in most cases failed to converge with PCM. The other two investigated compounds - 1,3-diisopropyl-urea (IPU) and methacrylic acid (MAAH) - were built up manually. Three structures were considered both for IPU ${ }^{\mathrm{a}, \mathrm{b}, \mathrm{c}}$ and trans-MAAH and cis-MAAH (Figure 2) for the further calculations determining the lowest energy geometrical structure of the complexes. Due to the high number of possible conformers 24 initial IPU-MAAH complex structures were built up and optimised both for 1:1 and 1:2 complexes. Natural bond orbital (NBO) analysis ${ }^{31}$ was performed to explain the binding properties of the complexes. The calculation of anharmonic frequencies as well as the usage of scaling factors was omitted, since the agreement between the measured and the calculated spectra was sufficiently good for most of the spectra even without considering these corrections. Due to the appearance of weak interactions (H-bonds), the calculated reaction energies were corrected utilizing the a posteriori counterpoise method of $\mathrm{BSSE}^{32}$. This error arises due to the finite basis sets which are centered on the atoms: the number of basis functions is different for the complex and the two initial compounds and the ghost orbitals can contribute to a larger decrease in the energy in the complex compared with the initial compounds. The computed geometries have been visualised using the GaussView 3.09 program.

\section{Results and discussion}

\subsection{Effect of the deprotonating agent on the complexation mechanism}

The investigation started with Continuous Variation Method (CVM) experiments, where IPU molefraction $\times \Delta \delta$ (chemical shift change) is plotted as a function of IPU mole fraction. The points on this curve are proportional to the concentration of the complex assuming solely 1:1 complexation (for details see Supporting Information 3.4). The results of the CVM are shown in Figure 2. The global maximum of the fitted curve occurs at about 0.57 mole fraction of IPU. This corresponds to a complex ratio of IPU:MAAH 
(1.33:1). This result shows may indicate: (i) the formation not only of 1:1 but 1:2 and 2:1 binary (ii) the possible self-association of IPU and (iii) the possible self-association of MAAH. Given the proportion of IPU:MAAH (1:4) in the prepolymerization solution ${ }^{6}$ the presence of IPU:MAAH(2:1) complex can be considered as negligible. Thus the present study focuses only on IPU:MAAH of 1:2.

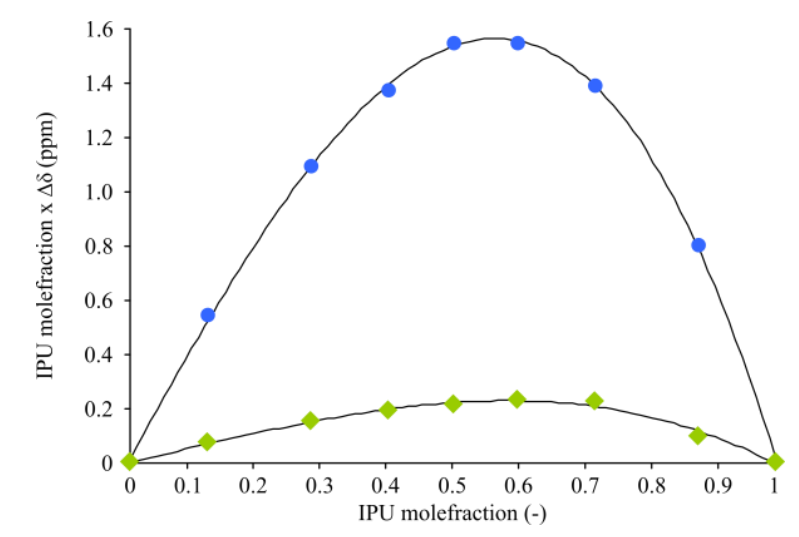

Figure 2. Job plot of the IPU-MAAH complex, the blue dots and green squares are attributed to the $\mathrm{H} 1$ and $\mathrm{H} 3$ signals of IPU, respectively (for the numbering of atoms see Figure 1); the total concentration IPU+MAAH was $20 \mathrm{mM}$.

IPU (the guest) is the observed species for the NMR titration experiments. In case of titration and Job's method its $\mathrm{H} 1(\mathrm{NH})$ and $\mathrm{H} 3(\mathrm{CH})$ protons were chosen, while in case of self-association experiments its $\mathrm{H} 1(\mathrm{NH})$ and $\mathrm{H} 4\left(\mathrm{CH}_{3}\right)$ protons were chosen to be followed throughout the corresponding NMR studies since significant shifts were observed for these hydrogens. The explanation of the discrepancy of the chosen hydrogens between the different reactions was aided by DFT calculations. In case of the IPU selfassociation, in the most stable dimers the methyl group (H4 hydrogen) is towards the other IPU carbonyl group, whereas the $\mathrm{H} 3$ proton is usually on the other side, making the creation of intermolecular hydrogen bond much more difficult to $\mathrm{H} 3$ than $\mathrm{H} 4$. In contrast, in the IPU:MAAH complexes in some non-ground state but minimum-type complex structures the MAAH O3 can form weak $\mathrm{H}$-bonds with $\mathrm{H} 3$ and $\mathrm{H} 4\left(\mathrm{CH}_{3}\right)$ of IPU, indicating also that the effect is much weaker for $\mathrm{H} 4$ (whose change of chemical shift was insignificant in the experiments) than for H3. These structures have energies in the range of 20-50 kJ.mol ${ }^{-1}$ above the ground state. Since the proportion of these higher-energy complex structures is assumed to be small, the total chemical shift difference within the NMR titration of $\mathrm{H} 3$ is expected to be smaller than that of H1 (ca. 0.5 ppm and 0.05 ppm for $\mathrm{H} 1$ and $\mathrm{H} 3$, respectively - vide infra: dataset $\mathrm{T} 2$ ).

To confirm that the observed chemical shifts are due to complexation between IPU and MAAH, two additional studies were carried out: (i) self-association of IPU; (ii) self-association of MAAH were assessed. Note that both for the IPU dimers and the most stable IPU:MAAH complexes the two NH signals (H1a and H1b signals) are not equivalent on molecular scale (one is H-bonded the other is not). The two NH signals of IPU split at lower concentrations when performing IPU:MAAH titration, at higher concentrations the broadening of the signal covers this difference. In case of the self-association the two distinct NH signals can be seen, however, both their chemical shift changes with concentration (see Figure 3). In case of the complex 
the more flexible MAAH groups will cause a very fast exchange and therefore the differences between the two NH will disappear. Whereas in the dimer due to the isopropyl groups the IPU is more rigid, thus the NH will be slightly split.
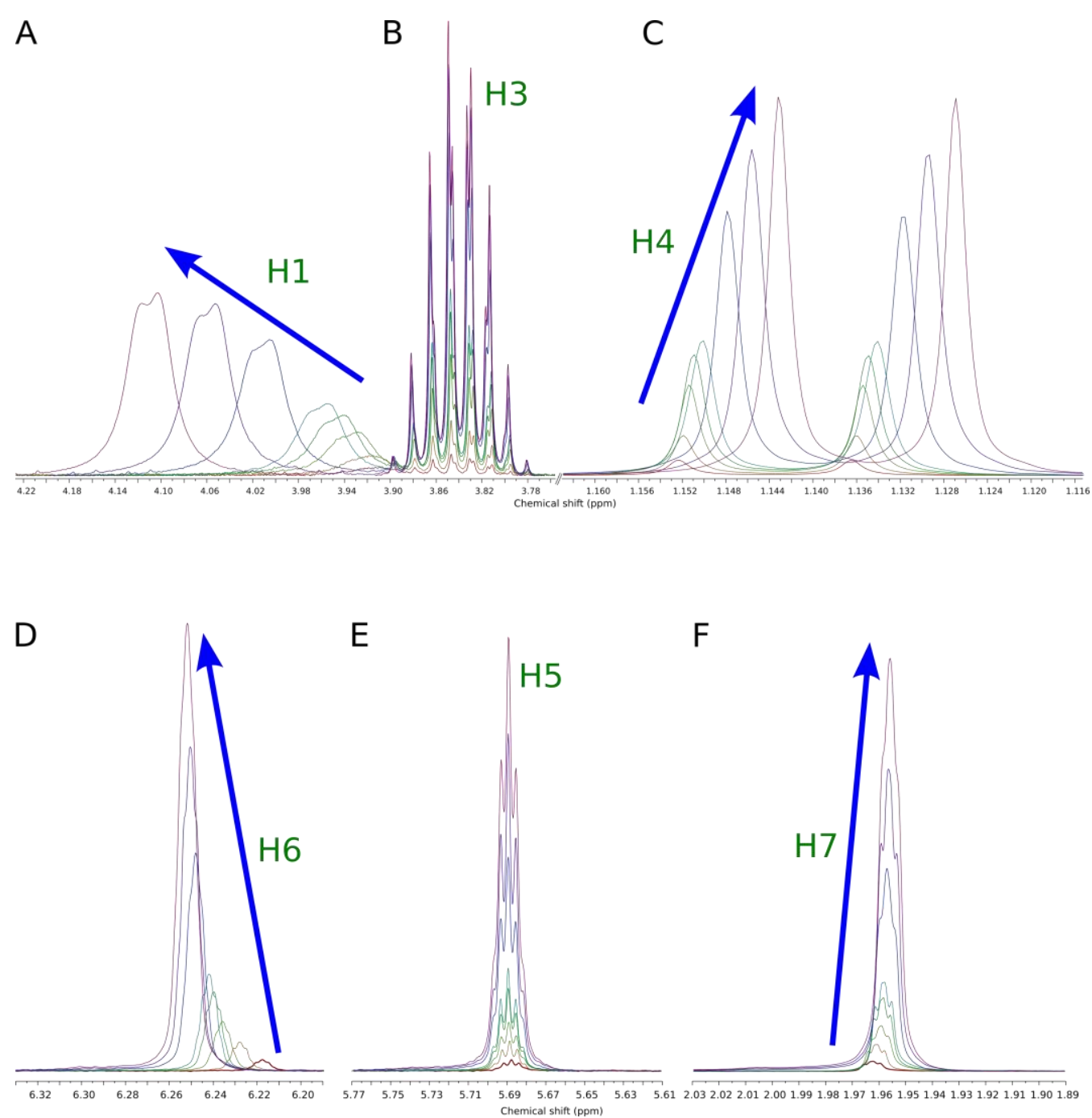

Figure 3. Self-association of IPU (top panel) and MAAH (bottom panel). Concentration range of 1-40 mM in $\mathrm{CDCl}_{3}$ indicating the (A) downfield shift of $\mathrm{H} 1$, the (B) no-shift of $\mathrm{H} 3$ and the (C) upfield shift of $\mathrm{H} 4$ in case of IPU and the (D) downfield shift of H6, the (E) no-shift of H5 and the (F) upfield shift of H7 in case of MAAH. For the numbering of atoms see Figure 1.

3.2. The self-association of the guest (IPU) and the host (MAAH)

Figure 3 shows the downfield shift $(0.201 \mathrm{ppm}$, Fig. 3A) and splitting of the H1 signals as well as the upfield shift (0.009 ppm, Fig. 3C) of the $\mathrm{H} 4$ doublet. Due to the low solubility of IPU (50 $\mathrm{mM}$ in $\mathrm{CDCl}_{3}$ at r.t.) the saturation of the self-association curve was not reached, however the self-association constant was estimated to be $0.502 \mathrm{dm}^{3} \cdot \mathrm{mol}^{-1}$ (the self-association calculations are described in the Supporting Information). As predicted, the association is unfavourable and it is only significant at high IPU concentrations or in the absence of MAAH, i.e. at the initial points of the NMR titrations. This is also supported by the complexation studies. If MAAH is present, the NH signal splitting can be noticed only at 
low MAAH concentrations. At higher MAAH concentrations the two H1a and H1b will become indistinguishable. The bottom panel of Figure 3 shows the downfield shift of H6 (0.034 ppm, Fig. 3D) and the upfield shift of $\mathrm{H} 7$ (0.007 ppm, Fig. 3F) of MAAH. The self-association constant of MAAH was estimated to be $360 \mathrm{dm}^{3} \cdot \mathrm{mol}^{-1}$. This value corresponds well with the previously determined value $\mathrm{e}^{33}$ of 330 $\mathrm{dm}^{3} \cdot \mathrm{mol}^{-1}$.

\subsection{Effect of the deprotonating agent on the complexation strength}

In order to investigate the binding strength between IPU and the functional monomer, two sets of NMR titrations were carried out at concentrations of 5 and $10 \mathrm{mM}$ IPU. The observed chemical shifts are shown in Figure 4 whilst a typical spectrum indicating all the chemical shifts of the studied system can be found in the Supporting Information in Figure S2. Figure 4 shows the two investigated datasets: with $5 \mathrm{mM}$ IPU (T1) and with $10 \mathrm{mM}$ IPU (T2) starting concentration, which was titrated with MAAH until 2 equivalents and 5 equivalents for datasets T1 and T2, respectively. For both measurements the IPU:MAAH (1:2) complex and the self-association constant of both IPU and MAAH were considered. The association constants and chemical shifts of the investigated compounds obtained are summarised in Table 1.

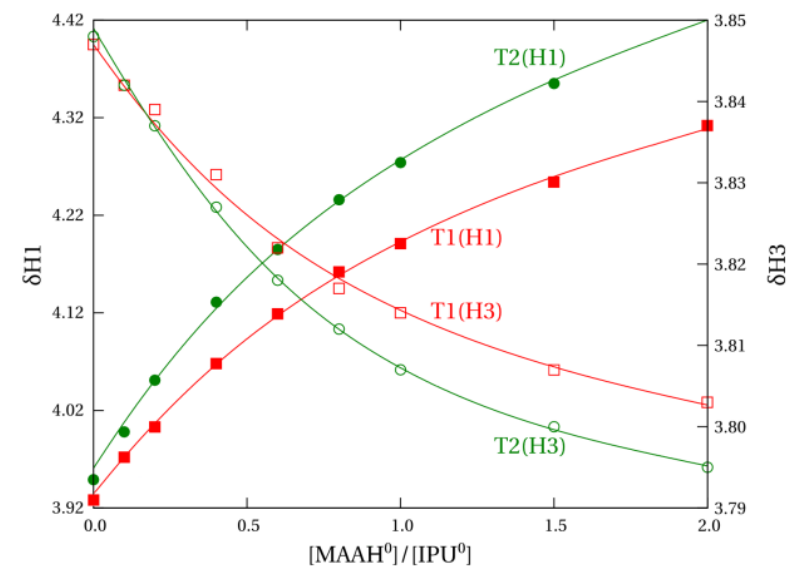

Figure 4. Measured chemical shifts of H1 (filled signs) and H3 (empty signs) and the fitted curves (lines) for the NMR titration of IPU-MAAH system where the red rectangular and green circular data sets represent titration $\mathrm{T} 1$ and $\mathrm{T} 2$ respectively where $\mathrm{T} 1$ (5 mM IPU) and T2 (10 mM IPU).

Table 1. Calculated association constants and observed chemical shifts of the H1 of IPU during the titration experiments. $\mathrm{s}^{2}$ means standard deviation of the fit.

\begin{tabular}{c|cc|cc|}
\hline & $\mathrm{T} 1(\mathrm{H} 1)$ & $\mathrm{T} 1(\mathrm{H} 3)$ & $\mathrm{T} 2(\mathrm{H} 1)$ & $\mathrm{T} 2(\mathrm{H} 3)$ \\
\hline $\mathrm{K}_{1}$ & 506 & 560 & 322 & 678 \\
$\mathrm{~K}_{2}$ & 6.02 & 1.54 & 5.94 & 14.98 \\
$\delta_{\mathrm{C}_{1}}$ & 4.508 & 3.774 & 4.656 & 3.775 \\
$\delta_{\mathrm{C}_{2}}$ & 11.269 & 3.019 & 11.640 & 3.747 \\
$\mathrm{~s}^{2}$ & $1.20 \times 10^{-3}$ & $3.35 \times 10^{-4}$ & $1.74 \times 10^{-3}$ & $1.05 \times 10^{-4}$ \\
$\mathrm{~K}_{1}$ average & \multicolumn{4}{|c}{$516 \pm 148$}
\end{tabular}


According to the conclusions drawn from the Job plot, the IPU-MAAH complexation is multi-step. Due to the complexity of the system - two step complexation and dimerization - a Python script was written (available as a Supporting Information). The calculated average values for the association constants and their standard deviations are summarised in Table 1.

The uncertainties of the equilibrium constants are relatively high partly due to the complex nature of the system, the low concentrations and thus the small changes in the chemical shift values and also because the water could be not completely removed from the system. The very high uncertainty of $\mathrm{K} 2$ can be explained by the fact that this association constant lies beyond the range of $10-10^{5} \mathrm{dm}^{3} \cdot \mathrm{mol}^{-1}$ in which the conventional NMR titrations are performed. In order to prove the importance of considering the higher order complexes and the self-association, the T1 and T2 NMR data representing the 5 and $10 \mathrm{mM}$ IPU titrations were, in addition, evaluated in a conventional fashion. Assumptions are often made in the literature during the evaluation of complexation studies of MIPs wherein higher order complexes and self-association are neglected. Following this approach and the widely applied Rose-Drago method ${ }^{34,35}$ the calculated $1 / \mathrm{K}$ is depicted as a function of the chosen set of $\Delta \delta_{\mathrm{MAX}}$ values. At different $\Delta \delta_{\mathrm{MAX}}$ values different lines are obtained which have a common intersection point giving the value of $1 / \mathrm{K}$ (for further details see equations S17-21 in the Supporting Information). Association constants of $525 \mathrm{dm}^{3} \cdot \mathrm{mol}^{-1}$ was obtained for the T1 dataset. In case of the T2 dataset due to both the higher initial IPU concentration the self-association and the higher final MAAH concentration the formation of 1:2 complexes are more pronounced the Rose-Drago plot gave an the standard deviation of the association constant in the same order of magnitude as the $\mathrm{K}$ itself. The Rose-Drago plot can be found in the Supporting Information in Figure S3. Evaluation of this data hence demonstrates that for IPU-MAAH system one has to consider self-association as well as higher order complexes.

\subsection{Geometrical parameters of the complexes}

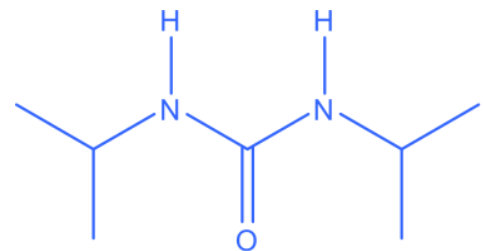

$\mathrm{IPU}^{\mathrm{a}}$

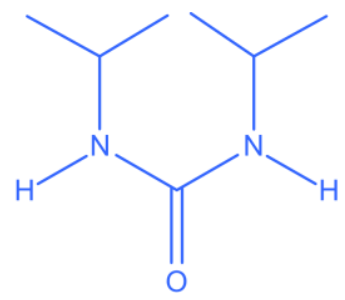

$\mathrm{IPU}^{\mathrm{b}}$

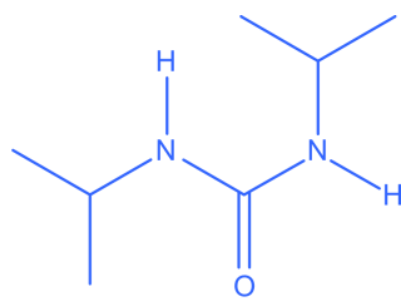

$\mathrm{IPU}^{\mathrm{c}}$

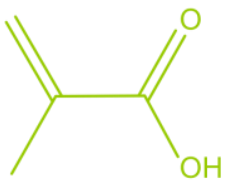

cis-MAAH

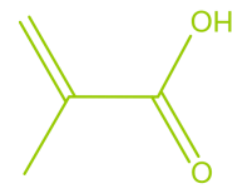

trans-MAAH

Figure 5. Schematic representation of the initial conformers of IPU and MAAH for further DFT calculations 
The theoretical calculations of the IPU and MAAH showed that the most stable conformers of these two compounds are IPU ${ }^{\mathrm{a}}$ and trans-MAAH (the different conformers of IPU and MAAH considered in the calculations are depicted in Figure 5), both for gas phase, implicitly treated DCM and $\mathrm{CHCl}_{3}$ solutions. Trans-MAAH has already been established by previous articles ${ }^{36,37}$. The difference of the ground state structure and the other two IPU conformers is significant with a value of $23 \mathrm{~kJ} \mathrm{~mol}^{-1}$ in gas phase, $25 \mathrm{~kJ}^{-\mathrm{mol}^{-}}$ ${ }^{1}$ in DCM and $35 \mathrm{~kJ}^{\mathrm{mol}}{ }^{-1}$ in $\mathrm{CHCl}_{3}$ for $\mathrm{IPU}^{\mathrm{b}}$ and $8 \mathrm{~kJ}^{\mathrm{mol}}{ }^{-1}$ in gas phase, $13 \mathrm{~kJ} \cdot \mathrm{mol}^{-1}$ in DCM and $10 \mathrm{~kJ} \cdot \mathrm{mol}^{-}$ ${ }^{1} \mathrm{in}_{\mathrm{CHCl}_{3}}$ for IPU ${ }^{\mathrm{c}}$. However, the energy difference between trans-MAAH and cis-MAAH is only marginal, being 1-2 kJ.mol ${ }^{-1}$ for gas phase and both solvents. The complexes were constructed considering all the sterically different structures.
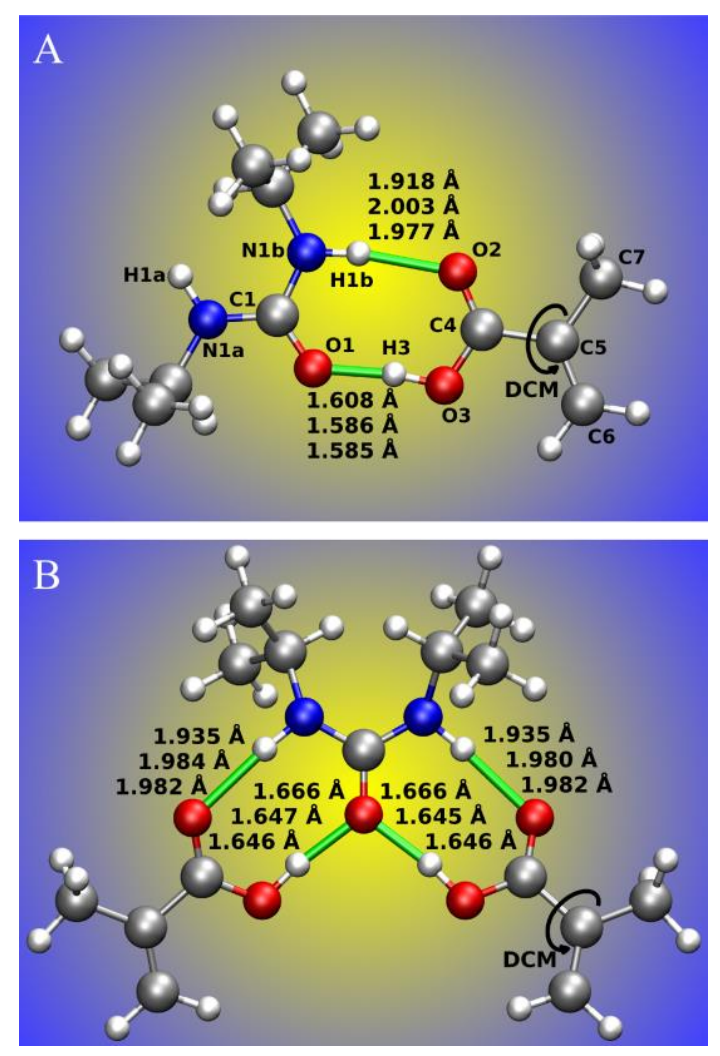

Figure 6. The most stable conformers of IPU-MAAH complexes with the H-bonds (depicted with green lines, distances from top to bottom: gas phase, $\mathrm{DCM}$ and $\mathrm{CHCl}_{3}$, respectively) given in angstroms: (A) 1:1 complex of IPU and MAAH (IPU ${ }^{\mathrm{c}}+$ trans-MAAH, except DCM, where IPU ${ }^{\mathrm{c}}+$ cis-MAAH), (B) 1:2 complex of IPU and MAAH (2xtrans-MAAH + IPU ${ }^{\mathrm{b}}$, except DCM, where trans-MAAH + cis-MAAH + $\left.\mathrm{IPU}^{\mathrm{b}}\right)$

The differences in the observed order of stability of the conformers between gas phase and $\mathrm{CHCl}_{3}$ solution are insignificant. Figure 6 shows the most stable structures of the complexes. The black arrows indicate that while in gas phase and chloroform the methacrylic acid is always present as trans, in dichloromethane for structures on Figure 6A and 6B one MAAH is present as cis.

To explain the differences between gas phase and the investigated solvents during complexation natural bond orbital analysis (NBO) was applied. Table 2 shows the NBO charges and Table 3 the charge transfers for the host and guest molecules and the 1:1 IPU:MAAH complex. The NBO charges in the gas phase differ significantly from those in which the solvents were considered. The interactions within the 
IPU:MAAH (1:1) complex are relatively heterogeneous. The charge of the N1b did not change significantly with the complexation, whereas O2 of MAAH moiety and O1 of IPU which both take part in hydrogen bonding became more negative (together $-0.129 e,-0.046 e$ and $-0.056 e$ in gas phase, $\mathrm{DCM}$ and $\mathrm{CHCl}_{3}$ ). $\mathrm{H} 1 \mathrm{~b}$ became more positive $(0.044 e, 0.012 e, 0.020 e)$, whereas $\mathrm{H} 3$ became more positive in gas phase and less positive in DCM and $\mathrm{CHCl}_{3}\left(0.032 e,-0.013 e,-0.004 e\right.$ for gas phase, $\mathrm{DCM}$ and $\mathrm{CHCl}_{3}$, respectively). The charge transfer for this complex shows strong delocalization of electrons in $(\mathrm{HN})-\mathrm{C}=\mathrm{O} \ldots \mathrm{H}-\mathrm{O}-\mathrm{C}=\mathrm{O} \ldots \mathrm{H}-$ $\mathrm{N}-(\mathrm{CO})$ ring. According to the two intermolecular charge transfers: $\mathrm{C} 1-\mathrm{O} 1 \rightarrow \mathrm{O} 3-\mathrm{H} 3$ of ca. $170 \mathrm{~kJ}^{\mathrm{mol}}{ }^{-1}$ and

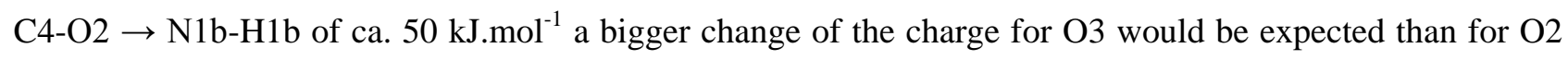
and that the N1b would be expected to become more negative. However, due to the strong delocalization, $\mathrm{O} 2$ got charge from the lone pair of $\mathrm{O} 3$ and the negative charge excess (compared to the unbound guest) of N1b disappeared with a charge transfer from the lone pair of N1b to $\mathrm{C} 1-\mathrm{O} 1$ antibonding orbital. The O1...H3 hydrogen bond is stronger in solutions than for the isolated molecule. Since both for $\mathrm{DCM}$ and $\mathrm{CHCl}_{3}$ the charge transfer to the antibonding orbital of $\mathrm{O} 3-\mathrm{H} 3$ from $\mathrm{C} 1-\mathrm{O} 1$ bonding and $\mathrm{O} 1$ lone pair is with ca. 20 $\mathrm{kJ} \mathrm{mol}^{-1}$ higher than in gas phase whereas the differences in backdonation are within $3 \mathrm{~kJ}^{\mathrm{mol}}{ }^{-1}$, this can indicate the reason of the opposite change of the charge for $\mathrm{H} 3$.

Table 2. Selected computed natural charges $(e)$ of $\operatorname{IPU}^{\mathrm{c}}$ and $1: 1$ complex of IPU and MAAH. For the numbering of atoms see Figure 1 and Figure 6.

\begin{tabular}{|c|c|c|c|c|c|c|}
\hline & \multicolumn{2}{|c|}{ gas phase } & \multicolumn{2}{|c|}{ DCM } & \multicolumn{2}{|c|}{$\mathrm{CHCl}_{3}$} \\
\hline & $\begin{array}{c}\mathrm{IPU}^{\mathrm{c}} / \\
\text { trans }-\mathrm{MAAH}\end{array}$ & $\begin{array}{c}\text { IPU:MAAH= } \\
(1: 1)\end{array}$ & $\begin{array}{c}\text { IPU }^{\mathrm{c} /} \\
\text { cis-MAAH }\end{array}$ & $\begin{array}{c}\text { IPU:MAAH= } \\
(1: 1)\end{array}$ & $\begin{array}{c}\text { IPU } / \\
\text { trans-MAAH }\end{array}$ & $\begin{array}{l}\text { IPU:MAAH } \\
\quad=(1: 1)\end{array}$ \\
\hline$\overline{\mathrm{C} 1}$ & 0.816 & 0.835 & 0.820 & 0.836 & 0.820 & 0.836 \\
\hline $\mathrm{O} 1$ & -0.684 & -0.742 & -0.758 & -0.778 & -0.746 & -0.767 \\
\hline N1b & -0.674 & -0.677 & -0.672 & -0.673 & -0.672 & -0.672 \\
\hline $\mathrm{H} 1 \mathrm{~b}$ & 0.393 & 0.437 & 0.416 & 0.428 & 0.412 & 0.432 \\
\hline $\mathrm{O} 2$ & -0.597 & -0.668 & -0.657 & -0.683 & -0.640 & -0.675 \\
\hline $\mathrm{O} 3$ & -0.695 & -0.703 & -0.701 & -0.711 & -0.705 & -0.714 \\
\hline H3 & 0.486 & 0.518 & 0.528 & 0.515 & 0.520 & 0.516 \\
\hline
\end{tabular}

Table 3. Main charge transfer interactions ${ }^{\mathrm{a}}$ in IPU:MAAH 1:1 complexes.

\begin{tabular}{rl|c|c|c}
\hline \multirow{2}{*}{ Charge transfer $\left(\mathrm{kJ}^{2} \mathrm{~mol}^{-1}\right)$} & \multicolumn{2}{|c|}{$\begin{array}{c}\text { gas } \\
\text { phase }\end{array}$} & DCM & $\mathrm{CHCl}_{3}$ \\
\cline { 3 - 5 } IPU:MAAH=(1:1) \\
\hline $\begin{array}{r}\text { BD C1-O1 } \\
\text { LP O1 }\end{array}$ & $\begin{array}{l}\text { BD* O3-H3 } \\
\text { RY* O3, H3 }\end{array}$ & 165.9 & 182.1 & 183.7 \\
\hline $\begin{array}{r}\text { BD C4-O2 } \\
\text { LP O2 }\end{array}$ & $\begin{array}{l}\text { BD* N1b-H1b } \\
\text { RY* N1b, H1b }\end{array}$ & 57.9 & 41.3 & 45.9 \\
\hline LP O3 $\rightarrow$ BD* C4-O2 & 278.3 & 270.7 & 273.2 \\
\hline LP N1b $\rightarrow$ BD* C1-O1 & 258.1 & 269.3 & 277.6 \\
\hline
\end{tabular}

${ }^{a}$ - Second-order perturbation energies (E(2) donor $\rightarrow$ acceptor, $\left.\mathrm{kJ} \cdot \mathrm{mol}^{-1}\right)$. The abbreviations LP, BD, BD* and $\mathrm{RY}^{*}$ mean lone pair, bonding, anti-boding and Rydberg orbitals, respectively. For the numbering of atoms see Figure 1 and Figure 6. 
IPU:MAAH (1:2) complex was also calculated and its structure is depicted in Figure 6B, which has a $\mathrm{C}_{2}$ symmetry in gas phase and $\mathrm{CHCl}_{3}$. In DCM solution one of the MAAH moieties is changed from trans to cis therefore the symmetry is broken in this case. The energy differences between this most stable DCM complex - featuring one trans-MAAH and one cis-MAAH conformers - and the less stable structures having

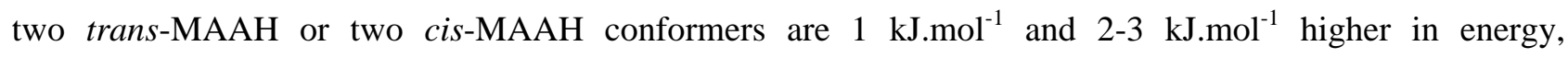
respectively. It is interesting to note that the most stable IPU:MAAH (1:2) complexes incorporate IPU $^{\mathrm{b}}$ conformer while the IPU:MAAH (1:1) complexes feature IPU ${ }^{\mathrm{c}}$ conformer. Despite of the fact that IPU $^{\mathrm{b}}$ is higher in energy than IPU ${ }^{\mathrm{c}}$ by a value of $15-24 \mathrm{~kJ} \mathrm{~mol}^{-1}$, the former conformer allows a better access to the $\mathrm{NH}$ and $\mathrm{C}=\mathrm{O}$ moieties which are the active sites of the complexation.

Table 4. Internal energies of complex or dimer formation reactions and the calculated Gibbs free energies from the measured association constant at $25{ }^{\circ} \mathrm{C}$ (the values are in $\mathrm{kJ} \cdot \mathrm{mol}^{-1}$ ). Multiple values are given as without/with BSSE correction.

\begin{tabular}{c|ccc|c}
\hline & \multicolumn{3}{|c|}{$\Delta \mathrm{E}($ calculated $) / \mathrm{kJ} \cdot \mathrm{mol}^{-1}$} & $\Delta \mathrm{G}\left(\right.$ measured $/ \mathrm{kJ}^{-\mathrm{mol}^{-1}}$ \\
& gas phase & DCM & $\mathrm{CHCl}_{3}$ & $\mathrm{CDCl}$ \\
\hline IPU (dimer) & $-38.7 /-35.9$ & $13.0 / 15.6$ & $3.2 / 5.7$ & 1.7 \\
MAAH (dimer) & $-66.9 /-63.6$ & $-17.4 /-14.0$ & $-23.6 /-20.2$ & -14.6 \\
IPU:MAAH (1:1) & $-59.0 /-55.8$ & $-11.3 /-8.2$ & $-17.7 /-15.9$ & -15.5 \\
IPU:MAAH (1:2) & $-96.4 /-89.9$ & $-11.2 /-4.9$ & $-27.0 /-23.3$ & -20.3 \\
\hline
\end{tabular}

The reactions leading to complex formation were also investigated and the corresponding reaction energies are summarised in Table 4. Note that in solution, due to both the existence of configurations with close lying energy levels and the presence of thermal perturbation, the simultaneous appearance of more complex structures is expected. Hence, the measured association constants cannot be assigned to one, welldefined structure. This is the main reason why the theoretically calculated energies cannot be directly compared to the Gibbs energies $(\Delta \mathrm{G})$ derived from the measurements. Nevertheless, trend is expected to be found between these theoretical and experimental values. The reaction energies related to the formation of the most stable conformers, were calculated for dimers, 1:1 and 1:2 complexes as shown in equation 1-3 (X stands for MAAH or IPU). For all compounds we considered the ground state structures obtained after geometry optimization. The associated Gibbs free energies were calculated from the measured association constants as given in equation 4 .

$$
\begin{aligned}
& \Delta \mathrm{E}(\text { dimer })=\mathrm{E}\left(\mathrm{X}_{2}\right)-2 \cdot \mathrm{E}(\mathrm{X}) \\
& \Delta \mathrm{E}(1: 1)=\mathrm{E}\left(\mathrm{C}_{1}\right)-\mathrm{E}\left(\mathrm{IPU}^{\mathrm{a}}\right)-\mathrm{E}(\text { trans-MAAH }) \\
& \Delta \mathrm{E}(1: 2)=\mathrm{E}\left(\mathrm{C}_{2}\right)-\mathrm{E}\left(\text { IPU }^{\mathrm{a}}\right)-2 \cdot \mathrm{E}(\text { trans-MAAH }) \\
& \Delta \mathrm{G}=-\mathrm{RT} \ln (\mathrm{K})
\end{aligned}
$$


Interestingly, a good agreement between $\Delta \mathrm{E}$ values from theoretical calculations and $\Delta \mathrm{G}$ values computed from the measured association constants were found, despite their different theoretical meaning. Both from the theoretical investigations and the measurements concluded that the IPU dimerization is disfavoured $(\mathrm{K}<1 ; \Delta \mathrm{G}>0)$, showing that the monomer concentration in the chloroform solution is higher than the dimer concentration for the used concentration ranges. For the rest of the investigated data $\Delta \mathrm{G}<0$ and thus $\mathrm{K}>1$ was found. Both the complex formations and the MAAH dimerization were found to be favourable. From the calculated results it can be concluded that the complexes and dimers are more stable in gas phase than in solutions. This is a consequence of the effect of the solvent which decreases the strength of the interactions between the parts of the complex ${ }^{38 E r r o r ! ~ B o o k m a r k ~ n o t ~ d e f i n e d . ~ T h e ~ s t a b i l i t y ~ o f ~ t h e ~ c o m p l e x e s ~ i s ~}$ higher for $\mathrm{CHCl}_{3}$ than DCM solutions. Therefore it would be expected that the equilibrium constants will be somewhat smaller in DCM solutions as those found in $\mathrm{CHCl}_{3}$.

Table 5. Measured and calculated IR bands of the complex compared to the measured spectra of MAAH and IPU.

\begin{tabular}{|c|c|c|c|c|c|c|c|}
\hline No & $\begin{array}{c}v_{\text {meas }} \\
{\left[\mathrm{cm}^{-1}\right]}\end{array}$ & Int $_{\text {meas }}{ }^{\mathrm{a}}$ & $\begin{array}{l}\mathrm{v}_{\text {MAAH }}{ }^{\mathrm{b}} \\
{\left[\mathrm{cm}^{-1}\right]}\end{array}$ & $\begin{array}{c}v_{\mathrm{IPU}}^{\mathrm{b}} \\
{\left[\mathrm{cm}^{-1}\right]}\end{array}$ & $\begin{array}{c}v_{\text {calc }} \\
{\left[\mathrm{cm}^{-1}\right]}\end{array}$ & $\begin{array}{c}\text { Int }_{\text {calc }} \\
{\left[\mathrm{km} \cdot \mathrm{mol}^{-1}\right]}\end{array}$ & Assignment ${ }^{\mathrm{c}}$ \\
\hline 1 & 951 & $\mathrm{~m}$ & 951 & - & 983 & 53 & $\delta_{\mathrm{r}} \mathrm{CH}_{2}, \mathrm{vC}-\mathrm{C}$ \\
\hline 2 & 1007 & $\mathrm{~W}$ & 1009 & - & 1026 & 26 & $\delta_{\mathrm{r}} \mathrm{CH}_{3}, \delta_{\mathrm{r}} \mathrm{CH}_{2}$ \\
\hline 3 & 1128 & $\mathrm{~W}$ & - & 1128 & 1142 & 29 & $\gamma_{\mathrm{s}} \mathrm{CH}_{3}, v_{\mathrm{as}} \mathrm{CC}$ \\
\hline 4 & 1177 & sh & 1178 & (1167) & 1181 & 83 & $\delta \mathrm{CNC}, \gamma_{\mathrm{s}} \mathrm{CH}_{3}, \beta_{\mathrm{sci}} \mathrm{CCC}$ \\
\hline 5 & 1204 & $\mathrm{~s}$ & 1204 & - & 1207 & 256 & trans: $v \mathrm{C}-\mathrm{O}, \beta \mathrm{OH}, \delta_{\mathrm{r}} \mathrm{CH}_{3}$ \\
\hline 6 & 1221 & $\mathrm{~m}$ & 1221 & - & 1229 & 281 & cis: $\vee \mathrm{C}-\mathrm{O}, \beta \mathrm{OH}, \delta_{\mathrm{r}} \mathrm{CH}_{3}$ \\
\hline 7 & 1300 & $\mathrm{~m}$ & 1300 & - & 1308 & 281 & $\beta \mathrm{OH}, \delta_{\mathrm{r}} \mathrm{CH}_{2}, v \mathrm{C}-\mathrm{C}$ \\
\hline 8 & 1317 & sh & 1320 & - & 1326 & 206 & $v \mathrm{C}-\mathrm{C}, \beta \mathrm{OH}, \nu \mathrm{C}-\mathrm{O}, \beta_{\mathrm{s}} \mathrm{OCO}$ \\
\hline 9 & 1375 & $\mathrm{~W}$ & 1375 & $\begin{array}{l}(1368) \\
(1385)\end{array}$ & 1378 & 53 & $\delta_{\mathrm{s}} \mathrm{CH}_{3}, \beta_{\mathrm{s}} \mathrm{CH}$ \\
\hline 10 & 1423 & $\mathrm{~m}$ & (1431) & 1423 & 1413 & 150 & $\delta_{\mathrm{s}} \mathrm{CH}_{3}$ \\
\hline 11 & 1454 & $\mathrm{~s}$ & 1454 & - & 1480 & 118 & $\delta_{\mathrm{as}} \mathrm{CH}_{3}, \delta_{\mathrm{sci}} \mathrm{CH}_{2}$ \\
\hline 12 & 1541 & $\mathrm{~m}$ & - & 1524 & 1573 & 664 & $\beta_{\mathrm{r}} \mathrm{NH} \ldots \mathrm{O}, \beta_{\mathrm{sci}} \mathrm{NCN}, \boldsymbol{\beta O H}$ \\
\hline 13 & 1636 & $\mathrm{~s}$ & 1636 & - & 1675 & 556 & $\mathrm{vC}=\mathrm{C}, \delta_{\mathrm{s}} \mathrm{CH}_{2}$ \\
\hline 14 & 1697 & vs & 1697 & $(1670)$ & 1650 & 498 & $v \mathrm{C}=\mathrm{O}$ \\
\hline 15 & 1732 & $\mathrm{~W}$ & 1730 & - & - & - & overtone/combination \\
\hline 16 & 2930 & $\mathrm{~m}$ & 2930 & $(2932)$ & 3019 & 25 & $v_{\mathrm{s}} \mathrm{CH}_{3}$ \\
\hline 17 & 2972 & $\mathrm{~s}$ & - & 2972 & 3027 & 22 & $v_{\mathrm{as}} \mathrm{CH}_{3}$ \\
\hline 18 & 3053 & $\mathrm{~W}$ & - & 3429 & 3437 & 707 & $\mathrm{v}_{\mathrm{S}} \mathrm{NH}$ \\
\hline
\end{tabular}

\footnotetext{
${ }^{\mathrm{a}}$ Measured intensity of the complex. The abbreviations vs, s, m, w and sh mean very strong, strong, medium, weak and shoulder, respectively.

${ }^{\mathrm{b}}$ Measured bands of MAAH and IPU. The bands in parentheses cannot be detected due to overlap.

${ }^{\mathrm{c}}$ The abbreviations $\mathrm{s}$, as, $v, \delta, \gamma, \beta$, sci, $\mathrm{r}$ mean symmetric, asymmetric, stretch, deformation, out-ofplane bending, in-plane bending, scissoring and rock, respectively.
}

The IR experiments confirmed the existence of these binding sites. The observed IR spectra of IPU, MAAH and IPU-MAAH system can be found in the Supporting Information in Figure S1. Detailed IR studies of MAAH in chloroform solution can already be found in the literature ${ }^{36,37}$ performed at level (MP2 6-31G(d,p), B3LYP 6-31G(d,p) and B3LYP 6-311+G(d,p)) which were used in the data evaluation. The measured IR spectra for the MAAH and both measured and calculated IR spectra for the IPU can be found in the Supporting Information (Tables S1 and S2, respectively). According to these results dimer formation was observed for MAAH, however the calculated IR spectra with the employment of scaling factors could describe the system. During the calculations the self-association of the IPU was not put into the model since 
according to the determined self-association constant (vide infra) the dimer concentration is around $1 \%$ at the concentration of measurements $(20 \mathrm{mM})$. The calculated harmonic spectra could be assigned to the measured with an average difference between the measured and calculated frequencies of $37.8 \mathrm{~cm}^{-1}$ for IPU. If $\mathrm{CH}_{3}$ stretching vibrations are not considered, which were overestimated by the calculations this difference is reduced to $19 \mathrm{~cm}^{-1}$ for IPU. The lack of significant hydrogen bonding in the spectra of IPU is supported by the quite narrow NH stretching vibrations in the region of $3330-3500 \mathrm{~cm}^{-1}$. However, for MAAH a quite broad signal can be found around $3000 \mathrm{~cm}^{-1}$, showing a significant hydrogen bonding.

Table 5 comprises the most important bands of the measured IR spectrum of 1:1 mixture of IPU:MAAH. In case of the most bands, either the IPU or the MAAH signals can be seen, which appear mostly at identical wavenumbers as on the spectrum of the two separate compounds. The $\beta_{\mathrm{r}} \mathrm{NH}$ band of the complex appears on the spectrum, however, there are two major differences compared with the same band of IPU: (i) the band is blue-shifted (it appears at $1541 \mathrm{~cm}^{-1}$, while the same band is at $1524 \mathrm{~cm}^{-1}$ in case of IPU) and (ii) the band is broadened. These two changes indicate the appearance of hydrogen bond in the system. Interestingly, the carbonyl band (between $1660-1700 \mathrm{~cm}^{-1}$ ) of the complex cannot be seen, instead only the carbonyl band of MAAH appears (at $1697 \mathrm{~cm}^{-1}$ ). The possible reason why we cannot observe the shifted carbonyl band of the complex is the broadening in complex compared to free IPU. Another important difference is the disappearance of the NH stretching vibrations of IPU (at $3339 \mathrm{~cm}^{-1}$ and $3429 \mathrm{~cm}^{-1}$ ). These $\mathrm{NH}$ vibrations should red-shift and broaden when hydrogen bonds form. Therefore the band at around $~ 3000$ and the peak at $3053 \mathrm{~cm}^{-1}$ in the spectrum of the complex can be assigned to the $\mathrm{NH}$ stretching vibration.

It is important to mention that the band at $1221 \mathrm{~cm}^{-1}$ appearing both in the complex and MAAH spectrum was not discussed in previous investigations ${ }^{36,37}$. We found that the $1204 \mathrm{~cm}^{-1}$ and $1221 \mathrm{~cm}^{-1}$ are showing the different conformers of MAAH, while the band at $1204 \mathrm{~cm}^{-1}$ belongs to trans-MAAH, the one at $1221 \mathrm{~cm}^{-1}$ belongs to the cis-MAAH conformer. This is consistent with the calculations. Firstly, the energy difference between the two conformers is around $1 \mathrm{~kJ} \mathrm{~mol}^{-1}$ which is sufficiently small to have both conformers present in the solutions at normal temperatures. Secondly, the calculated band intensity is 1.5 times larger for cis-MAAH than trans-MAAH (bands: $1137 \mathrm{~cm}^{-1}$ with intensity of $396 \mathrm{~km} \cdot \mathrm{mol}^{-1}$ and 1148 $\mathrm{cm}^{-1}$ with intensity of $547 \mathrm{~km} . \mathrm{mol}^{-1}$ for trans and cis-MAAH, respectively) and cis-MAAH since being the less stable, is present in slightly smaller amount. Thus the two bands belong to the same vibrations of the two conformers.

\section{Conclusions}

The MAAH and IPU complexation was investigated by NMR, IR and theoretical calculations. MAAH is one of the most abundant functional monomer for the preparation of molecularly imprinted polymers. The model system mimics the self-assembly taking place in the pre-polymerization solution of IPU imprinted scavengers. The NMR and quantum chemical investigation revealed a two-step complex formation mechanism in the absence of the deprotonating agent. The binding strengths were derived through quantum chemical calculations and NMR titrations for both 1:1 and 1:2 complexes. The quantum chemical 
calculations are in good agreement with the experimental observations, reaffirming the association constants. The theoretical calculations showed only minor differences in complexation between $\mathrm{DCM}$ and $\mathrm{CHCl}_{3}$. Due to the lack of information on higher-order complexes in the literature and in order to facilitate the complex data treatment thereof, a Python script treating both the 1:2 complex and self-association is provided in the Supporting Information.

\section{Acknowledgement}

Helpful comments on the calculation of binding constants from Balázs Krámos are gratefully acknowledged. The authors wish to thank also the computational time on the clusters of the Department of Inorganic and Analytical Chemistry of Budapest University of Technology and Economics and Université Paris-Est (Hugues Talbot). The authors are grateful for Sérgio Marques for the initial technical assistance with the NMR measurements.

Supporting Information: Python script for handling NMR titration data of higher-order complexes; Chemical shifts of IPU and MAAH; Rose-Drago plots; IR spectra; Mathematical framework of the NMR titration and the association constant. This material is available free of charge on the website of the publisher.

\section{References}

${ }^{1}$ B. Sellergren (Ed.), Molecularly Imprinted Polymers: Man-Made Mimics of Antibodies and Their Applications in Analytical Chemistry, Elsevier, Amsterdam, 2001.

${ }^{2}$ G. Szekely, I.B. Valtcheva, J.F. Kim, A.G. Livingston, React. Funct. Polym., 86, 2015, 215-224.

${ }^{3}$ M. Razali, J.F. Kim, M. Attfield, P.M. Budd, E. Drioli, Y.M. Lee, G. Szekely, Green Chem., 17, 2015, $5196-5205$.

${ }^{4}$ I. Dolak, R. Keçili, D. Hur, A. Ersoz, R. Say, Ind. Eng. Chem. Res., 54(19), 2015, 5328-5335.

${ }^{5}$ J. Kupai, E. Rojik, P. Huszthy, G. Szekely, ACS Appl. Mater. Interfaces, 7(18), 2015, 9516-9525.

${ }^{6}$ G. Szekely, J. Bandarra, W. Heggie, F.C. Ferreira, B. Sellergren, Sep. Purif. Technol. 86, 2012, 190-198.

${ }^{7}$ G. Szekely, B. Csordas, V. Farkas, J. Kupai, P. Pogany, Z. Santa, Z. Szakacs, T. Toth, M. Hollosi, J. Nyitrai, P. Huszthy, Eur. J. Org. Chem., 2012, 3396-3407.

${ }^{8}$ Laurent Caron, Caline Christine, Sebastien Tilloy, Eric Monflier, David Landy, Sophie Fourmentin, Gheorghe Surpateanu, Supramol. Chem., 14, 2002, 11-20

${ }^{9}$ Christiane Dethlefs, Jens Eckelmann, Hauke Kobarg, Thomas Weyrich, Stefan Brammer, Christian Näther, Ulrich Lüning, Eur. J. Org. Chem., 2011, 2011, 2066-2074

${ }^{10}$ Y. Zhang, D. Song, L.M. Lanni, K.D. Shimizu, Importance of functional monomer dimerization in the molecular imprinting process, Macromol., 43, 2010, 6284-6294.

11 A.J. Hall, P. Manesiotis, M. Emgenbroich, M. Quaglia, E. De Lorenzi, B. Sellergren, J. Org. Chem., 70(5), 2005, 1732-1736.

${ }^{12}$ Diane M. Kneeland, Katsuhiko Ariga, Vincent M. Lynch, Chia-Yu Huang, Eric V. Anslyn, J. Am. Chem. Soc., 115, 1993, 10042-10055

${ }^{13}$ P.A. Gale, J.R. Hiscock, C.Z. Jie, M.B. Hursthouse, M.E. Light, Chem. Sci., 1, 2010, 215-220.

${ }^{14}$ B. Liu, L. OU, F. Zhang, Zh. Zhang, H. Li, M. Zhu, Sh. Wang, J. Sep. Science, 37(23), 2014, 1615-9314

${ }^{15}$ T.-P. Huynh, B. K. C. Chandra, M. Sosnowska, J. W. Sobczak, V. N. Nesterov, F. D'Souza, W. Kutner, Biosens. Bioelectr., 64, 2015, 657-663.

${ }^{16}$ K. K. Tadi, R. V. Motghare, J. Mol. Model., 19(8), 2013, 1610-2940.

${ }^{17}$ J. Liu, Zh. Dai, B. Li, Sh. Tang, R. Jin, J. Mol. Model., 20(10), 2014, 2456.

${ }^{18}$ S. A. Piletsky, K. Karim, E. V. Piletska, C. J. Day, K. W. Freebairn, C. Legge, A. P. F. Turner, Analyst, 126, 2001, 1826-1830.

${ }^{19}$ S. Shoravi, G. D. Olsson, B. C. G. Karlsson, I. A. Nicholls, Int. J. Mol. Sci., 15(6), 2014, 10622-10634.

${ }^{20}$ H.E. Gottlieb, V. Kotlyar, A. Nudelman, NMR, J. Org. Chem., 62, 1997, 7512-7515.

${ }^{21}$ Frisch, M. J.; Trucks, G. W.; Schlegel, H. B.; Scuseria, G. E.; Robb, M. A.; Cheeseman, J. R.; Montgomery Jr., J. A.; Vreven, T.; Kudin, K. N.; Burant, J. C.; Millam, J. M.; Iyengar, S. S.; Tomasi, J.; Barone, V.; Mennucci, B.; Cossi, M.; 
Scalmani, G.; Rega, N.; Petersson, G. A.; Nakatsuji, H.; Hada, M.; Ehara, M.; Toyota, K.; Fukuda, R.; Hasegawa, J.; Ishida, M.; Nakajima, T.; Honda, Y.; Kitao, O.; Nakai, H.; Klene, M.; Li, X.; Knox, J. E.; Hratchian, H. P.; Cross, J. B.; Bakken, V.; Adamo, C.; Jaramillo, J.; Gomperts, R.; Stratmann, R. E.; Yazyev, O.; Austin, A. J.; Cammi, R.; Pomelli, C.; Ochterski, J. W.; Ayala, P. Y.; Morokuma, K.; Voth, G. A.; Salvador, P.; Dannenberg, J. J.; Zakrzewski, V. G.; Dapprich, S.; Daniels, A. D.; Strain, M. C.; Farkas, O.; Malick, D. K.; Rabuck, A. D.; Raghavachari, K.; Foresman, J. B.; Ortiz, J. V.; Cui, Q.; Baboul, A. G.; Clifford, S.; Cioslowski, J.; Stefanov, B. B.; Liu, G.; Liashenko, A.; Piskorz, P.; Komaromi, I.; Martin, R. L.; Fox, D. J.; Keith, T.; Al-Laham, M. A.; Peng, C. Y.; Nanayakkara, A.; Challacombe, M.; Gill, P. M. W.; Johnson, B.; Chen, W.; Wong, M. W.; Gonzalez, C.; Pople, J. A. Gaussian 03, Revision E.01, Gaussian, Inc., Wallingford CT, 2004.

${ }^{22}$ A. D. Becke, J. Chem. Phys., 98, 1993, 5648-5652.

${ }^{23}$ C. Lee, W. Yang, R. G. Parr, Phys. Rev. B, 37, 1988, 785-789.

${ }^{24}$ J. Tonannavar, Y. B. Chavan, J. Yenagi, Spectrochim. Acta A, 149, 2015, 860-868.

${ }^{25}$ J. Tonannavar, Y. B. Chavan, J. Yenagi, Spectrochim. Acta A, 160, 2016, 19-25.

${ }^{26}$ J. B. Foersman, Æ. Frisch, Exploring Chemistry with Electronic Structure Methods (2)Gaussian, Inc, Pittsburgh, PA, 1996

27 Amarendra Kumar, Vijay Narayan, Onkar Prasad, Leena Sinha, Monomeric and dimeric structures, electronic properties and vibrational spectra of azelaic acid by HF and B3LYP methods, J. Mol. Struct., 1022, 2012, 81-88.

${ }^{28}$ M. Cossi, V. Barone, R. Cammi, J. Tomasi, Chem. Phys. Lett., 255, 1996, 327-335.

${ }^{29}$ R. Cammi, B. Mennucci, J. Tomasi, J. Phys. Chem. A, 104, 2000, 5631-5637.

${ }^{30}$ M. Cossi, G. Scalmani, N. Rega, V. Barone., J. Chem. Phys., 117, 2002, 43-54.

${ }^{31}$ E. D. Glendening, J. K. Badenhoop, A. E. Reed, J. E. Carpenter, J. A. Bohmann, C. M. Morales, F. Weinhold, NBO 5.0; Theoretical Chemistry Institute, University of Wisconsin: Madison, 2001.

${ }^{32}$ S. F. Boys, F. Bernardi, Mol. Phys., 19, 1970, 553-566.

${ }^{33}$ Richard J. Ansell, Dongyao Wang, Janice K. L. Kuah, Analyst, 133, 2008, 1673-1683.

${ }^{34}$ Norman J. Rose, Russell S. Drago, J. Am. Chem. Soc., 81, 1959, 6138-6141.

${ }^{35}$ H. N. Wachter, V. Fried, J. Chem. Educ., 51, 1974, 798-799.

${ }^{36}$ J. Saloni, S. S. R. Dasary, Y. Anjaneyulu, H. Yu, G. Hill Jr., Struct. Chem., 21, 2010, 1171-1184.

${ }^{37}$ H.M. Badawi, M.A.A. Al-Khaldi, S.S.A. Al-Abbad, Z.H.A. Al-Sunaidi, Spectrochim. Acta A, 68, 2007, $432-442$.

${ }^{38}$ A. Bhaskarapillai, S. Chandra, N.V. Sevilimedu, B. Sellergren, Biosens. Bioelectr., 25, 2009, 558-562. 